\title{
PREVALENCE OF PARTIAL THICKNESS ROTATOR CUFF TEAR IN YOUNGER POPULATION (20 - 40 YEARS)- A CADAVERIC STUDY
}

\author{
Vijayarahavan Pugalenthi', Rathinam Arivasan², Thangamuthu Saravanamuthu³, Ganapathi Shankara Shanmuga Sethu ${ }^{4}$
}

1 Professor and HOD, Department of Orthopaedic and Traumatology, Madurai Medical College, Madurai, Tamilnadu.

2Professor, Department of Orthopaedic and Traumatology, Madurai Medical College, Madurai, Tamilnadu.

${ }^{3}$ Assistant Professor, Department of Orthopaedic and Traumatology, Madurai Medical College, Madurai, Tamilnadu.

${ }_{4}^{4}$ Postgraduate Student, Department of Orthopaedic and Traumatology, Madurai Medical College, Madurai, Tamilnadu.

ABSTRACT
BACKGROUND
Most of the rotator cuff injuries are left unnoticed in the early period, because of lack of knowledge and evidence of its prevalence
and later on they present in an inoperable state at younger age. There is a discrepancy between cadaver and clinical studies because
intratendinous tears are more difficult to diagnose with arthroscopy, MRI or ultrasound than bursal or articular tears.

\section{MATERIALS AND METHODS}

We performed a cadaveric study in the Department of Orthopaedics, Madurai Medical College. Rotator cuff muscles (Supraspinatus and infraspinatus) were dissected from fresh cadavers of both sexes on both sides, excluding those with soft tissue or bony injuries regardless of the cause of death. 75 rotator cuff specimens, dissected from 40 cadavers in Mortuary, Government Rajaji Hospitals under guidance of Forensic Medicine Department, Madurai Medical College with age at death between 20 and 40 years (mean age29.22 years) were analysed for the prevalence of macroscopic and microscopic partial thickness tear (PTT) and in occupation requiring overhead activities.

\section{RESULTS}

In our study, overall prevalence of PTT in young cadaveric population (20 - 40 years) was found to be $10 \%$. Bursal sided PTT $(7.5 \%)$ are more common than articular (2.5\%). All 4 subjects had tear bilaterally $(100 \%)$.

\section{CONCLUSION}

The lower prevalence of PTT in younger age group suggests an age-related degeneration in the pathogenesis of rotator cuff tear. As there is a strong evidence of bilateral presence, it is important to screen asymptomatic contralateral shoulder in patients with RCT.

\section{KEY WORDS}

Partial Thickness Tear, Articular, Bursal, Interstitial Tear.

HOW TO CITE THIS ARTICLE: Pugalenthi V, Arivasan R, Saravanamuthu T, et al. Prevalence of partial thickness rotator cuff tear in younger population (20 - 40 years)- a cadaveric study. J. Evolution Med. Dent. Sci. 2018;7(19):2380-2384, DOI: $10.14260 /$ jemds/2018/536

\section{BACKGROUND}

Significant pathology in rotator cuff can occur over a wide range of age from teenage to nineties and involves a wide range of pathology from minimal inflammation to full thickness tear. Rotator cuff tears are due to a combination of injury and weakening of the cuff tendon due to repeated microtrauma, ${ }^{[1]}$ repeated steroid injections and smoking, etc. In younger individuals with healthy rotator cuff, as in overhead athletes, repeated microtrauma is the cause for the rotator cuff tear. It produces a significant disability as it limits the abduction, internal rotation and produces significant pain in overhead activities. Forceful depression of an elevated arm (Eccentric force) or sudden jerky lift of the shoulder (Concentric force) is the most common cause of the rotator cuff injuries in younger population. ${ }^{[2]}$

'Financial or Other Competing Interest': None.

Submission 28-02-2018, Peer Review 20-04-2018,

Acceptance 27-04-2018, Published 19-05-2018.

Corresponding Author:

Shankara Shanmuga Sethu Ganapathi,

No. 15, Viruppampalayam, Kodumudi Post,

Erode-638151, Tamilnadu.

E-mail: gsethu18@gmail.com

DOI: $10.14260 /$ jemds $/ 2018 / 536$

(c) $($ ) $९$
As there is an increasing incidence of trauma cases, the number of patients with soft tissue injuries is in rise. Most of those injuries of shoulder like rotator cuff injuries are left unnoticed in the early period because of lack of knowledge and evidence of its prevalence and later on they present in an inoperable state at a younger age.

There is a discrepancy between cadaver and clinical studies, because intratendinous tears are more difficult to diagnose with arthroscopy, MRI or ultrasound than bursal or articular tears.[3] In the past literature the cadaveric population tends to be older than those in the radiological studies and so the prevalence of tears was found to be higher than actual prevalence. $[4,5,6,7,8,9]$ So in our study we included only the younger population from 20 - 40 years to aid in acknowledging the importance of aetiology of chronic shoulder pain in younger population.

\section{MATERIALS AND METHODS}

This prevalence survey was undertaken in the Department of Orthopaedics, Madurai Medical College and Govt. Rajaji Hospital, Tamilnadu in concurrence with the Department of Forensic Medicine and the Department of Pathology, Madurai Medical College, Madurai, between August 2015 and September 2017.

With the approval of the Ethical Committee and the Department of Forensic Medicine, rotator cuff sections were 
dissected from cadavers in Mortuary, Govt. Rajaji Hospital under the guidance of the Department of Forensic Medicine, Madurai Medical College, Madurai. In this study, rotator cuff specimens were studied macroscopically while dissecting and then microscopically in the Department of Pathology at Madurai Medical College, Madurai.

We were provided with the details of the subjects regarding name, age, sex, nature of the profession and evidence of any injury in the upper limb. No information on the lifestyle of the subjects, on the history of shoulder complaints and on the hand dominance was available. All autopsies were performed within 24 hours after death. Rotator cuff muscles (Supraspinatus and Infraspinatus) were dissected from fresh cadavers of both sexes on both sides excluding those with soft tissue or bony injuries in the upper limb regardless of the cause of death. 75 rotator cuff specimens were dissected from 40 cadavers with age at death between 20 and 40 years (Average age- 29.22 years). Partial thickness rotator cuff tear is an incomplete tear as it damages the tendon, but does not completely sever it.

\section{Study Design}

A cross-sectional study.

\section{Samples Studied}

75 Rotator Cuff Specimens.

\section{Rotator Cuff Dissection}

With the subject lying supine and sandbag under the ipsilateral scapula, we proceeded dissection after excluding soft tissue or bony injury in the ipsilateral shoulder and upper limb. We made the dissection by beginning at the anterior aspect of the shoulder along the anterior margin of the lateral one-third of the clavicle and extended around the acromion laterally and along the lateral half of the spine of the scapula posteriorly and along the anterior margin of the deltoid muscle to a point two-thirds the distance between its origin and insertion. Detached the origin of the deltoid from the scapula and clavicle and reflected it laterally to visualise the anterior, superior and posterior parts of the bursal surface of rotator cuff.

Rotator cuff muscles were inspected for any obvious tear on the bursal surface. Supraspinatus and infraspinatus muscles (full thickness) were marked for about $3 * 3 \mathrm{~cm}$ dimension just along their insertion into greater tuberosity laterally and the anterior margin of supraspinatus anteriorly. Marked region of rotator cuff is dissected except along their insertion laterally and the dissected part is reflected to expose the articular surface and examined for any macroscopic tear. Free medial end is now tagged along the bursal side with yellow thread for left side and red thread for right shoulder. Now the lateral end is also sectioned.

Section is fixed in $10 \%$ formalin solution and sent for histopathological examination of Rotator cuff specimens which was done in the Department of Pathology at Madurai Medical College, Madurai to find out the microscopic tear on bursal or articular side or intratendinous tear as indicated by Hashimoto (2003)[10] collagen fibre disorientation, chondroid metaplasia, fibroblast proliferation and fatty degeneration, inflammatory cell infiltration, myxoid degeneration. From each specimen, 3 slides were prepared; one each from bursal, articular and intratendinous portion-
- $\quad$ Age at death/ sex: 24/F.

- Occupation: Homemaker.

- Specimen: Bilateral.

- Macroscopic: No Tear.

- Microscopic: B/L Bursal Tear.

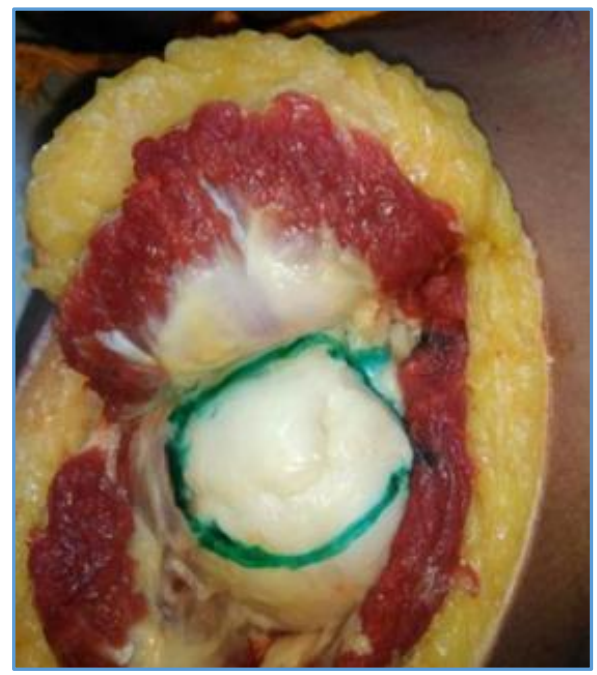

Bursal Surface

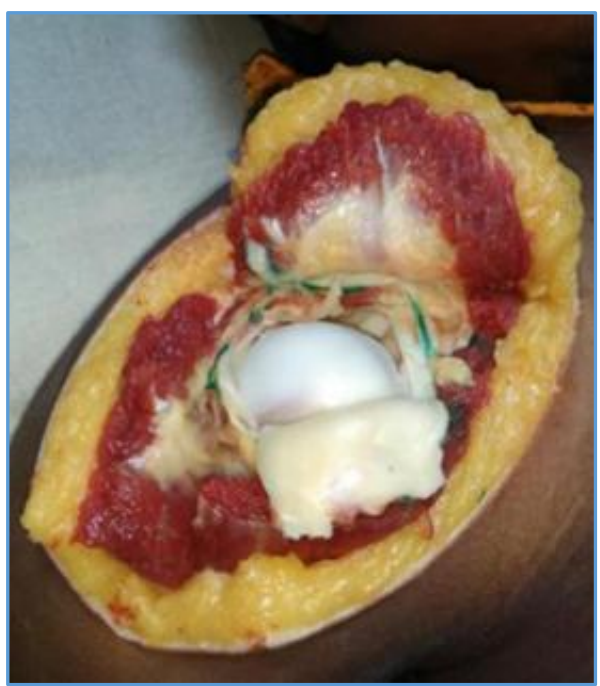

Articular Surface

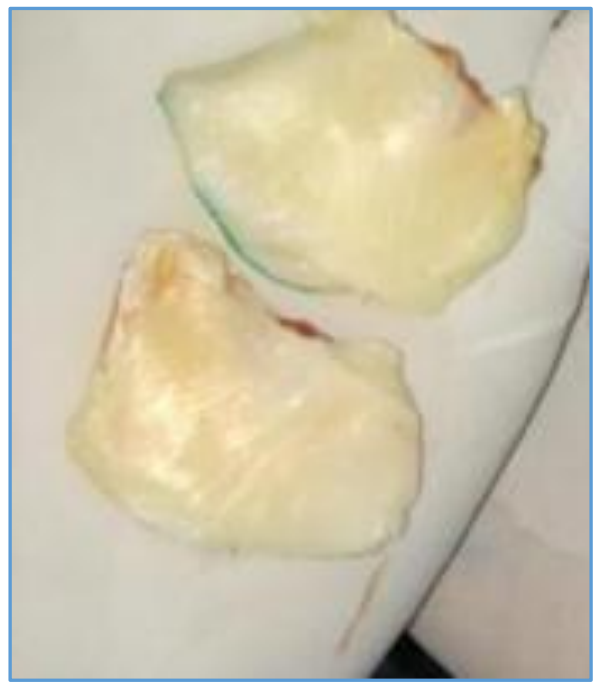

Articular Surface 


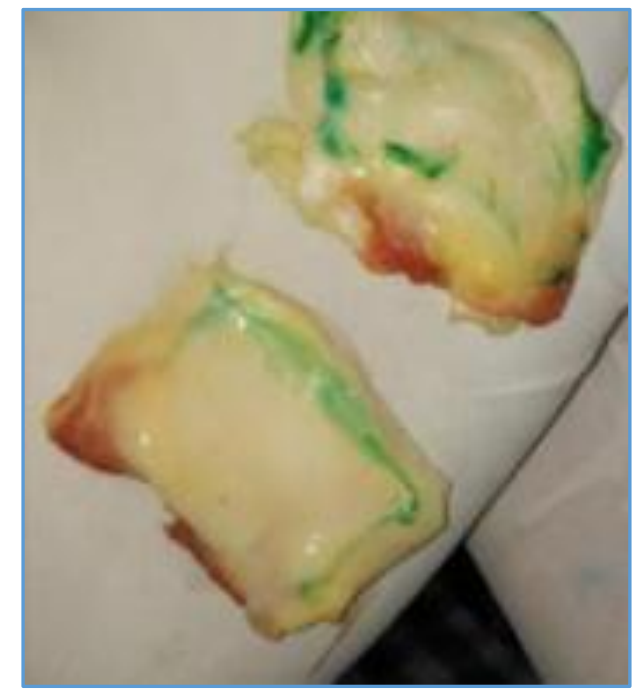

Bursal Surface

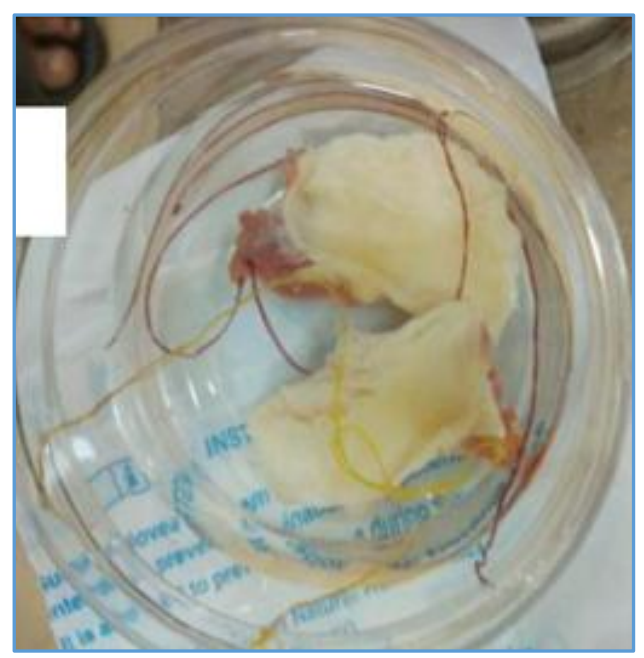

Bursal slide showing myxoid degeneration with focal chondroid metaplasia (right). $\mathrm{H}$ and $\mathrm{E}$ stain, original magnification x10.

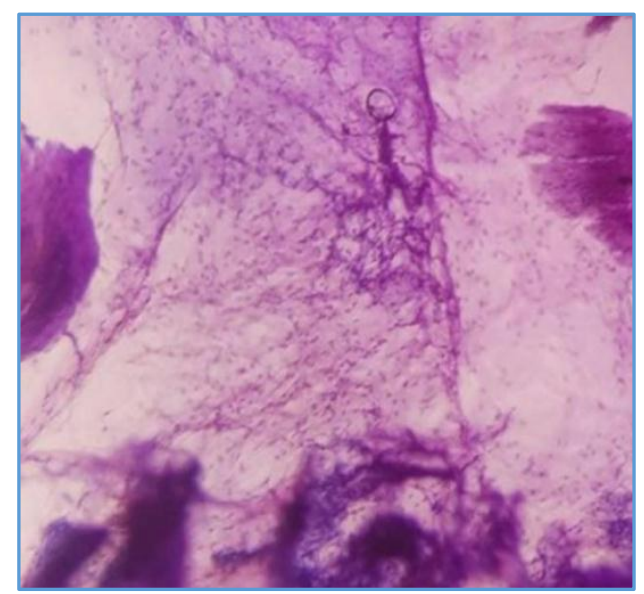

- $\quad$ Age at Death/ sex: 40/M.

- Occupation: Manual Labourer.

- Specimen: Bilateral.

- Macroscopic: B/L Articular Tear.

- Microscopic: B/L Articular Tear.

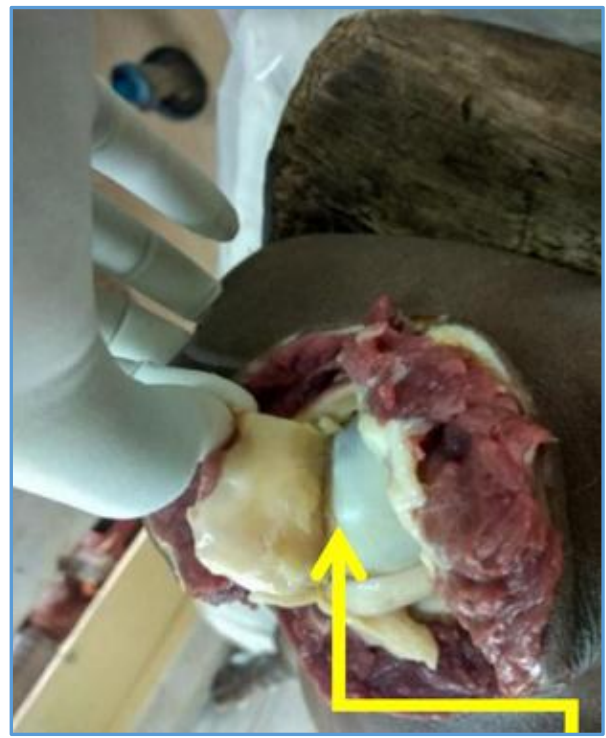

Right Shoulder

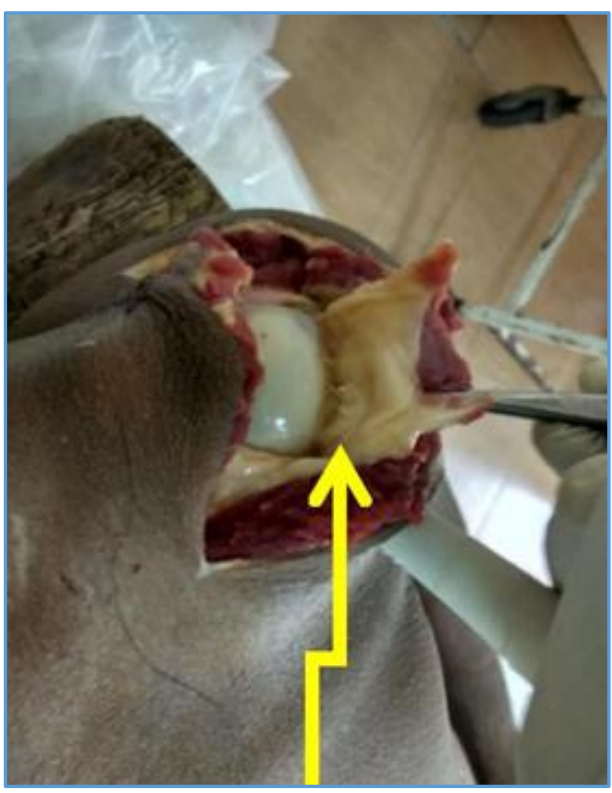

Left Shoulder

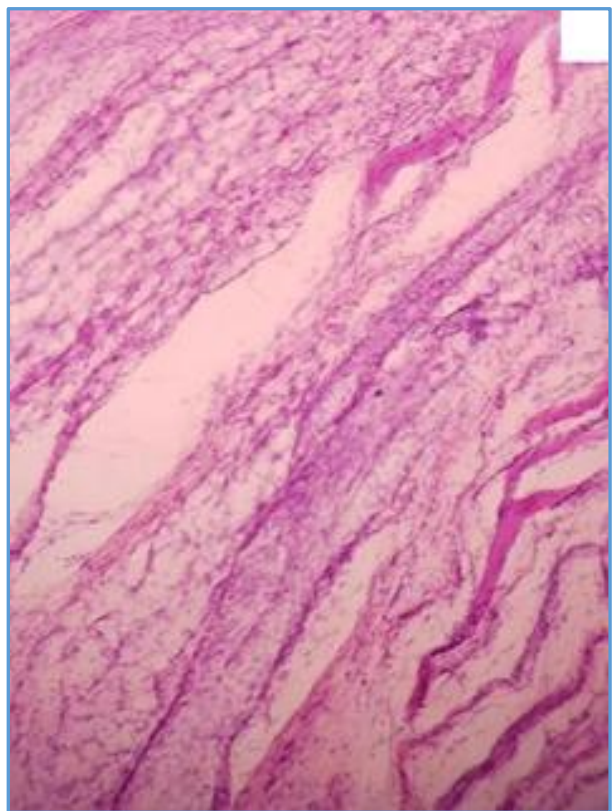

Macroscopic Tear in Articular Surface 
Articular slide showing disoriented collagen fibres with focal thinning and collagen split, $\mathrm{H}$ and $\mathrm{E}$ stain, original magnification $\mathrm{x} 10$.

\section{DISCUSSION}

In the past literature, the cadaveric population tends to be older $[4,5,6,7,8,9]$ than those in the radiological studies and so the prevalence of tears was found to be higher than actual prevalence. So in our study, we included only the younger population from 20 - 40 years.

This study reviewed the prevalence of partial thickness rotator cuff tears in the cadaveric populations irrespective of symptoms. As no clinical data on shoulder complaints are available for the cadaveric population,[11] it is reasonable to assume that as in any large sample, some had symptomatic shoulders. The prevalence of rotator cuff tear in asymptomatic subjects as determined by magnetic resonance imaging (MRI) and ultrasonography should be lower than the prevalence in cadaveric population. Conversely, the radiological prevalence of rotator cuff tears in a population with symptomatic shoulders should be higher than the prevalence in cadaveric population.

The prevalence of PTT in cadaveric population as per our study was found to be $10 \%$, which correspond with literature (PTT-18.49\%). In the population we studied, the partial thickness rotator cuff tear prevalence was $7.69 \%$ in $20-30$ years population and $14.28 \%$ in 31 - 40 years population. This difference is significant enough to show that prevalence of PTT increases with age.[12,13] As none of our cadaveric population has FTT, we are of the opinion that the size of the PTT progresses with age to evolve into FTT.[14]

We found that the prevalence of PTT in males $(9.38 \%)$ is lower than that in females (12.5\%). But this difference is insignificant as the p-value is more than 0.05 .

Among 35 subjects dissected bilaterally, partial thickness rotator cuff tear was found in 4 subjects and all those 4 subjects had tear bilaterally $(100 \%)$ and none of them had unilateral tear. This correlates with the study by Liem and Buschmann(15) suggesting the contralateral involvement in patients previously operated for partial thickness tear.

PTT occur with nearly equal frequency on either side in our study (right- 10.5\%, left- 10.8\%). This difference is insignificant. This did not support the opinion in the literature that RCT of the dominant extremity are more common. Nearly half of the RCT we observed were in the left shoulder, while it is highly unlikely that half of our study population are left handed.

The bursal sided PTT (7.5\%) are more common than the articular sided PTT (2.5\%) and interstitial tears $(0 \%)$, which is in contrary to the literature that the interstitial tears are more common than articular sided and bursal sided tears as studied by Yamanaka et al[16] with a prevalence of $3 \%$ on bursal side, $3 \%$ on articular side and $7 \%$ were intratendinous. This may be because the interstitial tears are more commonly due to degeneration[14] that occurs with age and our study population includes younger age group than that in the literature.[17]

Interstitial tears were not observed in our study population. Hence, we are of opinion that the interstitial tears are more commonly due to ageing process like degeneration.[18]

\section{CONCLUSION}

Overall prevalence of partial thickness rotator cuff tear in the young cadaveric population aged between 20 and 40 years in this study is $10 \%$. The prevalence of rotator cuff tear increases with age suggesting age-related degeneration in the pathogenesis of rotator cuff tear. As there is a strong evidence of bilateral presence of rotator cuff tear, it is important to screen the asymptomatic contralateral shoulder in patients with rotator cuff tear. On the contrary, there is no correlation between the handedness of individual and the development of rotator cuff tear as both sides have equal prevalence in our study and also the overhead activities do not have significant influence on the development of rotator cuff tear.

\section{REFERENCES}

[1] Neer CS. Impingement lesions. Clin Orthop Relat Res 1983;173:70-7.

[2] Skinner HA. Anatomical considerations relative to rupture of the supraspinatus tendon. J Bone Joint Surg 1937;19(1):137-51.

[3] Cotton RE, Rideout D. Tears of the humeral rotator cuff: a radiological and pathological necropsy survey. J Bone Joint Surg Br 1964;46:314-28.

[4] Keyes EL. Observations on rupture of supraspinatus tendon. Based upon a study of 73 cadavers. Ann Surg 1933;97(6):849-56.

[5] Lehman C, Cuomo F, Kummer FJ, et al. The incidence of full thickness rotator cuff tears in a large cadaveric population. Bull Hosp J Dis 1995;54(1):30-1.

[6] Uhthoff HK, Loehr J, Sarkar K. The pathogenesis of rotator cuff tears. Proceedings of the third international conference on surgery of the shoulder, Fukuora Oct 27, 1986: p. 211-2.

[7] Ozaki J, Fujimoto S, Nakagawa Y, et al. Tears of the rotator cuff of the shoulder associated with pathological changes in the acromion. A study in cadavers. J Bone Joint Surg Am 1988;70(8):1224-30.

[8] Pieper HG, Radas C. The prevalence of rotator cuff tear. Proceedings of the International Congress on Surgery of the Shoulder, Sydney, Australia, 1998: p. 64.

[9] Grant JCB, Smith CG. Age incidence of rupture of the supraspinatus tendon. Anat Rec 1948;100:666-9.

[10] Hashimoto T, Nobuhara K, Hamada T. Pathologic evidence of degeneration as a primary cause of rotator cuff tear. Clin Orthop Relat Res 2003;415:111-20.

[11] Smith JG. The classic: pathological appearances of seven cases of injury of the shoulder joint with remarks. Clin Orthop Relat Res 2010;468(6):1471-5.

[12] Fukuda H. Rotator cuff tears. Geka Chiryo (Osaka) 1980;43: p.28.

[13] Fukuda H, Mikasa M, Ogawa K, et al. The partial thickness tear of rotator cuff. Orthop Trans 1983;173:70-7.

[14] Wilson CL, Duff Gl. Pathological study of degeneration and rupture of the supraspinatus tendon. Arch Surg 1943;47(2):121-35.

[15] Liem D, Buschmann VE, Schmidt C, et al. The prevalence of rotator cuff tears: is the contralateral shoulder at risk? Am J Sports Med 2014;42(4):826-30.

[16] Yamanaka K, Fukuda H, Hamada K, et al. Incomplete thickness tears of the rotator cuff. Orthop Traumatol Surg (Tokyo) 1983;26:713. 
[17] Codman EA. The shoulder: rupture of the supraspinatus tendon and other lesions in or about the subacromial bursa. Boston: Thomas Todd Co 1934.
[18] Lindblom K, Palmer I. Ruptures of the tendon aponeurosis of the shoulder joint. Acta Chir Scand 1939;82:133-42. 